\title{
PULMONARY INFECTIONS IN CHILDREN WITH A PARTIAL THORACIC STOMACH ('HIATUS HERNIA')
}

\author{
BY \\ I. J. CARRÉ \\ From the Department of Child Health, The Queen's University, Belfast
}

(RECEIVED FOR PUBLICATION JANUARY 25, 1960)

During the early stages of a clinical study of the partial thoracic stomach ('hiatus hernia') in children a number of patients were seen who appeared unduly susceptible to pulmonary infections. This observation suggested a possible relationship between the two conditions. The following review was undertaken with the object of either proving or disproving this contention.

\section{Method}

The impossibility of obtaining for comparison figures relating to the incidence of pulmonary infections in the childhood population and the lack of objective data upon which to base conclusions presented two major difficulties in carrying out this survey. It was considered that these difficulties could be largely overcome if a suitable sub-division of patients was devised making it possible to compare two groups of children within the series. Such a procedure would dispense with the need of a control group for comparison and, at the same time errors inevitably introduced as a result of varying interpretations of the terms 'bronchitis' and 'pneumonia' would be largely eliminated as these would theoretically occur with equal frequency in either group.

Of necessity, the data for this analysis have been largely derived from the clinical history obtained from parents. A statement to the effect that the child had had either 'bronchitis' or 'pneumonia' as diagnosed by the family doctor has been accepted as a pulmonary infection for the purpose of this survey.

Should there exist a tendency for children with a partial thoracic stomach to develop pulmonary infections it seemed logical to infer that such infection might be related either to the type or frequency of symptoms associated with the patient's gastrooesophageal abnormality. For this reason the severity of the gastro-oesophageal symptoms has been used as a basis for analysing the data relating to these patients. The following two symptom groups have been defined based on a previous classification (Carré, 1959):

Group X: Vomiting and/or difficulty in swallowing solid food occurring on average more frequently than once a month.

Group Y: Vomiting and/or difficulty in swallowing solid food occurring on average less often than once a month.

Such a classification, however, does not provide for a clearcut sub-division of patients because of the symptomatic improvement shown by the majority with advancing age (Carré, 1959). It is apparent that at a particular age a child's symptoms might conform to Group X severity but a year later be those of Group Y. To overcome this difficulty each patient has been classified as having symptoms of either Group X or Y severity for each year of age. For example, a child who suffered from frequent symptoms for more than six months of the age period 1-2 years would be classified under Group X for that period, and similarly would be reclassified under Group $Y$ for the age period 2-3 years if symptoms had subsided to conform with this grouping.

In this way two series of 12 monthly age periods have been obtained. On the one hand a series consisting of annual periods during the major portion of which symptoms of Group X severity were recorded and on the other hand a series of annual periods during which less troublesome symptoms were noted (Group Y). In addition, the occurrence of pulmonary infections, night vomiting and dysphagia with solid food have been recorded in respect of each annual age period.

\section{Selection of Patients}

Children considered in this survey all had a small portion of stomach protruding into the chest through the oesophageal hiatus. The gastrooesophageal junction was in every instance situated along the upper border of the intra-thoracic gastric 
TABLE 1 ASSOCIATION OF PULMONARY INFECTION WITH FREQUENCY AND TYPE OF VOMITING

\begin{tabular}{|c|c|c|c|c|c|c|c|}
\hline \multirow{2}{*}{$\begin{array}{l}\text { Age } \\
\text { Period } \\
\text { (years) }\end{array}$} & \multirow{2}{*}{$\begin{array}{l}\text { Clinical } \\
\text { Group }\end{array}$} & \multirow[b]{2}{*}{$\begin{array}{l}\text { No. of } \\
\text { 12-monthly } \\
\text { Age } \\
\text { Periods }\end{array}$} & \multicolumn{5}{|c|}{ No. of 12-monthly Periods During which Following Symptoms were Noted } \\
\hline & & & $\begin{array}{l}\text { Pulmonary } \\
\text { Infection }\end{array}$ & Dysphagia & $\begin{array}{l}\text { Dysphagia } \\
\text { and } \\
\text { Pulmonary } \\
\text { Infection }\end{array}$ & $\begin{array}{c}\text { Night } \\
\text { Vomiting }\end{array}$ & $\begin{array}{c}\text { Night } \\
\text { Vomiting } \\
\text { and Pulmonary } \\
\text { Infection }\end{array}$ \\
\hline $1-2$ & $\begin{array}{l}\mathbf{X} \\
\mathbf{Y}\end{array}$ & $\begin{array}{l}37 \\
41\end{array}$ & $\begin{array}{r}15 \\
2\end{array}$ & $\begin{array}{r}13 \\
2\end{array}$ & $\begin{array}{l}2 \\
0\end{array}$ & $\begin{array}{r}30 \\
3\end{array}$ & $\begin{array}{r}15 \\
0\end{array}$ \\
\hline $2-3$ & $\underset{\mathbf{Y}}{\mathbf{X}}$ & $\begin{array}{l}22 \\
52\end{array}$ & $\begin{array}{l}6 \\
8\end{array}$ & $\begin{array}{l}7 \\
2\end{array}$ & $\begin{array}{l}1 \\
1\end{array}$ & $\begin{array}{r}14 \\
5\end{array}$ & $\begin{array}{l}5 \\
1\end{array}$ \\
\hline $3-4$ & $\underset{\mathbf{Y}}{\mathbf{X}}$ & $\begin{array}{l}19 \\
30\end{array}$ & $\begin{array}{l}5 \\
4\end{array}$ & $\begin{array}{r}12 \\
2\end{array}$ & $\begin{array}{l}4 \\
0\end{array}$ & $\begin{array}{r}13 \\
2\end{array}$ & $\begin{array}{l}4 \\
0\end{array}$ \\
\hline 4-5 & $\underset{\mathbf{Y}}{\mathbf{X}}$ & $\begin{array}{r}9 \\
18\end{array}$ & $\begin{array}{l}0 \\
2\end{array}$ & $\begin{array}{l}5 \\
1\end{array}$ & $\begin{array}{l}\mathbf{0} \\
\mathbf{0}\end{array}$ & $\begin{array}{l}4 \\
4\end{array}$ & $\begin{array}{l}0 \\
1\end{array}$ \\
\hline $1-5$ & $\underset{\mathbf{Y}}{\mathbf{X}}$ & $\begin{array}{r}87 \\
141\end{array}$ & $\begin{array}{l}26 \\
16\end{array}$ & $\begin{array}{r}37 \\
7\end{array}$ & $\begin{array}{l}7 \\
1\end{array}$ & $\begin{array}{l}61 \\
14\end{array}$ & $\begin{array}{r}24 \\
2\end{array}$ \\
\hline
\end{tabular}

Group X Attacks of vomiting and/or dysphagia occurring more frequently than once a month during at least six months of any one year of age.

Group Y Fewer symptoms than Group X.

loculus. Surgically treated patients have been excluded.

As it was intended to compare the occurrence of pulmonary infections with specific clinical disturbances, such as night vomiting and difficulty in swallowing solid food, the age period reviewed has been restricted to over 1 year, when both these features could be more accurately determined. With relatively few children over 5 years available for study this age has been adopted as the upper limit for consideration.

Except where specifically stated the following analysis is restricted to patients who had no associated oesophageal stricture. Information relating to 78 patients has provided 228 annual periods for analysis.

\section{Results}

A pulmonary infection was recorded for 26 of the 87 annual age periods (29.9\%) during which symptoms were classified as of Group X severity and for 16 of 141 periods $(11.3 \%)$ during which symptoms were minimal, Group Y (Table 1). This difference in incidence is statistically significant $(p<0.001)$. $^{*}$ These observations confirm that pulmonary infections are commoner in children with a partial thoracic stomach during periods when vomiting is frequent.

In theory this significantly higher recorded incidence of pulmonary infections during Group X annual periods could be related not to the frequency of symptoms but to the occurrence either of dysphagia with solid food or night vomiting, both of which were frequently noted clinical features during these periods. To test this hypothesis a further analysis of Group X periods has been undertaken as follows.
Difficulty in swallowing solid food was a recorded symptom during 37 of the 87 Group $X$ annual periods; a pulmonary infection was recorded during seven of these 37 periods $(18.9 \%)$. The comparable figures for periods during which dysphagia was not a complaint were 19 of $50(38 \%)$. However, when annual periods were excluded during which night vomiting was also a feature these figures become two of $19(10.5 \%)$ and none of seven respectively. Information relating to patients with an associated oesophageal stricture has been analysed in a similar manner. In all these children the predominant and often only symptom was difficulty in swallowing solid food. In only four of 37 annual periods was a pulmonary infection noted, an incidence of $10.8 \%$. Allowing for the small figures involved, these latter estimates $(10 \cdot 5,0$ and $10.8 \%$ ) conform with the observed frequency of pulmonary infections during the Group $Y$ periods $(11.3 \%)$ when clinical disturbances were judged to be infrequent. The occurrence of dysphagia therefore appears to have no direct bearing on the increased incidence of pulmonary infections noted during periods of frequent symptoms.

On the other hand, a pulmonary infection was recorded during 24 of 61 annual Group X periods $(39.3 \%)$ during which night vomiting was a feature. The comparable figures for Group $\mathrm{X}$ periods during which night vomiting was not a complaint were two of $26(7 \cdot 7 \%)$. This difference is statistically significant $(0.01>p>0.001)$. Furthermore, the frequency of pulmonary infections during Group $\mathrm{X}$ periods when night vomiting was not recorded $(7 \cdot 7 \%)$ is similar to that estimated for Group $Y$ $(11 \cdot 3 \%)$. 


\section{Radiological Observations}

Segmental pulmonary lesions have been identified radiologically on 19 occasions in 17 of 242 children with a partial thoracic stomach (Table 2). These lesions were confined to the right lung in 13 and the left in four; in two instances both lungs were involved. A single lobe was involved in 16 instances. In 10 of the 12 right-sided lesions the affected area was either the middle or upper lobe. Of the four left-sided lesions the upper lobe was the affected site in two.

At the time of demonstrating these lesions eight patients were aged less than 12 months, seven were between 1 and 3 years old and four were more than 3 years of age.

TABLE 2

RADIOLOGICALLY CONFIRMED PULMONARY LESIONS

\begin{tabular}{l|c|cc} 
& \multicolumn{2}{|c|}{$\begin{array}{c}\text { Lobe of Lung Affected } \\
\text { Patient }\end{array}$} & \multicolumn{2}{|c}{$\begin{array}{c}\text { Age } \\
\text { (Collapse/Consolidation) }\end{array}$} & (yrs) (mths) \\
\hline T.B. & R.U. & \multicolumn{1}{c}{10} \\
A.S. & R.M. & 7 & 2 \\
E.W. & L.U. & 1 & 3 \\
D.Ru. & R.L. & 1 & 11 \\
R.Ha. & L.U. & 9 \\
R.Gi. & R.M. & 1 & 1 \\
M.W. & R.M. and L.U. & 1 & 4 \\
W.J. & R.M. & 4 & 6 \\
C.N. & L.L. & 1 & 2 \\
S.G. & R.M. & & 2 \\
A.S. & R.M. & & 7 \\
P.W. & R.U. & & 2 \\
M.L. & R.U. & 3 & 1 \\
J.D. & L.U. and R.M. & 7 & 0 \\
J.M. & R.L. and R.M. & 2 & 8 \\
D.H. & L.L. & 2 & 9 \\
S.S. & R.M. & & \\
\hline
\end{tabular}

Lobe affected: $\quad$ R.U. = right upper $\quad$ R.M. = right middle R.L. = right lower L.U. = left upper $\quad$ L.L. = left lower

* In all quoted statistical analyses $p<0.05$ has been accepted as evidence of significance.

\section{Discussion}

It has been shown that in children with a partial thoracic stomach the risk of acquiring a pulmonary infection is greatly increased if vomiting at night is a symptom. In the present study the occurrence of night vomiting was associated with more than a threefold increase in the number of recorded pulmonary infections. On the other hand no relationship could be demonstrated between the development of pulmonary infections and either frequent day vomiting or dysphagia with solid food.

These findings suggest that many of the pulmonary infections recorded in children with a partial thoracic stomach result from the inhalation of vomited material at a time when the patient is in a semi-conscious state. The radiological observa- tions recorded in this study are interpreted as supporting such a contention. These show a preponderance of single lobe lesions with the right lung principally affected, a distribution demonstrated by Brock, Hodgkiss and Jones (1942) as characteristic of the inhalation of foreign material during recumbency. However, an unusually large number of right middle lobe lesions were noted in the present series. This may be due to the fact that while still only half awake many patients will sit up and lean forward when vomiting thereby assuming a posture suited to the inhalation of material into the right middle lobe bronchus (Foster-Carter, 1943).

Radiographically defined pulmonary lesions were most frequently noted in patients under 3 years of age. In view of the association between night vomiting and pulmonary infections these findings are to be expected as most children with a partial thoracic stomach suffer from progressively fewer gastro-oesophageal symptoms (including night vomiting) as they grow older (Carré, 1959).

\section{Summary}

A study is described in which the occurrence of pulmonary infections in children with a partial thoracic stomach has been related to specific symptoms referable to the patient's gastro-oesophageal abnormality. The results indicate that the incidence of pulmonary infections in children with a partial thoracic stomach is considerably increased if night vomiting is a symptom. On the other hand there is no reason to believe that frequent day vomiting or difficulty in swallowing solid food predispose to the development of pulmonary infections.

Evidence is quoted in support of the view that many of the pulmonary infections noted in patients with night vomiting result from the inhalation of vomited material.

I am greatly indebted to Dr. R. Astley of the Children's Hospital, Birmingham, and Dr. F. Plarre of the Royal Children's Hospital, Melbourne, Australia, for the radiological assessment of the patients considered in this study. I wish to thank also the consultant physicians and surgeons of the Children's Hospital, Birmingham, the Royal Children's Hospital, Melbourne, and the Royal Belfast Hospital for Sick Children for permission to review their patients and Mr. J. D. Merrett of Queen's University, Belfast, for help with the statistical analysis.

References
Brock, R. C., Hodgkiss, F. and Jones, H. O. (1942). Bronchial embolism and posture in relation to lung abscess. Guy's Hosp. Rep., 91, 131.

Carré, I. J.' (1959). The natural history of the partial thoracic stomach ('hiatus hernia') in children. Arch. Dis. Childh. 34, 344.

Foster-Carter, A. F. (1943). An outline of bronchial anatomy. Proc. roy. Soc. Med., 36, 451. 